\title{
Editorial: Chlamydia, trachoma, genital infection, and psittacosis
}

In 1957, Tang, Chang, Huang, and Wang isolated the aetiological agent of trachoma. Jones and coworkers reported the isolation of the agents responsible for inclusion blennorrhoea of the newborn eye and the genital tract of the parents (Jones, Collier, and Smith, 1959) and also responsible for inclusion conjunctivitis, Tric-agent punctate keratoconjunctivitis (TPK), and trachoma in adults in London (Jones, I96r ; Jones, I964; Jones, Al-Hussaini, and Dunlop, 1964). They subsequently reported the isolation of identical agents from the genital tract of men presenting with so-called "non-specific" urethritis (NSU) (Dunlop, Al-Hussaini, Garland, Treharne, Harper, and Jones, 1965) and from the genital tract or rectum of their sexual partners (Dunlop, Hare, Darougar, Jones, and Rice, 1969; Darougar, Kinnison, and Jones, 197I ; Dunlop, Hare, Darougar, and Jones, 1971).

The subsequent work that has gone a long way towards establishing that at least half of the patients presenting with "NSU" are in fact presenting with chlamydial urethritis has recently been reviewed (Lancet, 1974).

Because these various agents, at the time when they were isolated, could not be easily distinguished one from another, and because the eye disease associated with the agents isolated in London formed a continuous spectrum ranging in severity from inclusion conjunctivitis to trachoma, it was agreed to use the term TRIC agent for these organisms (TR for trachoma, Ic for inclusion conjunctivitis) (Gear, Gordon, Jones, and Bell, r963). These trachoma-inclusion conjunctivitis agents belong to the group of organisms that has variously been called the PL group or the PLT group of agents (psittacosis lympho-granuloma trachoma), or the Bedsonia in recognition of the isolation and characterization by Sir Samuel Bedson of the agent of psittacosis. The term Bedsonia is still used by some authors and its passing is lamented by most workers in this field. However, for technical reasons of taxonomy, it has been generally agreed to use the name Chlamydia for the genus (Page, 1966).

Within the genus, two species are at present recognized: Chlamydia trachomatis and Chlamydia psittaci (Page, 1968).

C. trachomatis is taken to include all the TRIC agents. At present the generally more invasive agents isolated from lymphogranuloma venereum (Schachter and Meyer, 1969) are not separated from C. trachomatis; even though they have a number of biological characteristics that distinguish them from TRIC agents (Kuo, Wang, and Grayston, 1972).
All these agents produce iodine-staining inclusion bodies and are subgroup A Chlamydia by the classification of Gordon and Quan (1965).

C. psittaci was isolated from patients suffering from psittacosis, but, pending possible future subdivision, is taken to cover all iodine negative (subgroup B) Chlamydia of animal and avian origin. Some of these agents infect the respiratory tract or occasionally the eye of man (Schachter, Ostler, and Meyer, I969; Ostler, Schachter, and Dawson, I969).

Further changes in the generic name being unlikely, we can look forward to increasing awareness of the importance of chlamydial eye disease in developed countries where TRIC agents ( $C$. trachomatis), very largely of microimmunofluorescence serotypes $\mathrm{D}, \mathrm{E}$, F, G, H, or I, are responsible for a sizeable proportion of the more severe external ocular infections, frequently unrecognized but ranging through the syndromes of inclusion conjunctivitis, TPK, to trachoma. In Great Britain, these are of frequent genital transmission and are transferred occasionally to the eye. For these infections, in whatever site, it is convenient to revive Lindner's term: paratrachoma (Dwyer, Treharne, Jones, and Herring, 1972).

There is an increasing awareness of the widespread prevalence of chlamydial urethritis, chlamydial cervicitis, chlamydial proctitis, etc., caused mainly by TRIC serotypes D, E, F, G, H, and I. The application of appropriate laboratory diagnostic methods is providing a sound basis for rational antibiotic therapy of these conditions (Lancet, 1974).

In rural areas of the developing world, hyperendemic trachoma and related infections continue to constitute the largest single cause of preventable blindness in the world as a whole (World Health Organization, 1973). Hyperendemic trachoma of eye-to-eye transmission is caused by TRIC agents, very largely of microimmunofluorescence serotypes A, B, $\mathrm{Ba}$, and $\mathrm{C}$, but also to some extent by some of the serotypes more frequently associated with paratrachoma (Jones, 1974; Wang and Grayston, 1974).

Readers of this journal will note a series of papers dealing with various advances in diagnostic methods for chlamydial infections. From a comparison of various tests (Jones, 1974), it is clear that the method of centrifugation of clinical specimens onto monolayers of irradiated McCoy cells (Gordon, Dressler, and Quan, 1967) has provided techniques for primary isolation and cultivation of Chlamydia that offer the most sensitive methods of detecting the organism in individual clinical specimens. It has been suitably streamlined to make it practicable for large-scale 
epidemiological studies (Darougar, Kinnison, and Jones, 197I). Furthermore, there has been good correlation between the grade of intensity of clinical signs of active upper tarsal conjunctival disease in trachoma, and the percentage of positive isolates from conjunctival swabbings. With standardized techniques, the laboratory methods can thus be used to assess the prevalence and intensity of active stages of trachoma in a population and to make comparisons between different populations, or assess the effect of various measures to control the disease.

In the paper by Darougar, Kundu, and Jones (1974), the method of isolation using DEAE-Dextran treated HeLa 229 cells was assessed in comparison with the irradiated McCoy cell technique. This method, devised by Kuo, Wang, Wentworth, and Grayston (1972) is simpler but slightly less sensitive than the McCoy cell technique and is much superior to isolation in fertile hen eggs. Wentworth and Alexander (1974) have recently shown that iododeoxyuridine treatment may be substituted for the more complicated irradiation of McCoy cells to increase their suitability for cultivation of Chlamydia.

Nevertheless, in spite of the much higher sensitivity of the new cultural methods for laboratory diagnosis of chlamydial infection, the much simpler diagnostic procedure of finding inclusions in Giemsa-stained conjunctival scrapings still has a place in large-scale studies of trachoma and its prevention. In this issue (p. 116), Yoneda, Dawson, Daghfous, Hoshiwara, Jones, Messadi, and Schachter (1975) discuss and illustrate the recognition of TRIC agent inclusions and the various other intracellular objects that may be mistaken for inclusions. In an extensive study of scrapings from cases of hyperendemic trachoma in Tunisia, to per cent of the smears were positive. Inclusions were present only in smears containing numerous polymorphonuclear leucocytes and in which the conjunctival epithelial cells were separated, rather than lying in large sheets. With these two features alone, 3 per cent. of smears were positive. If lymphocytes were also present, 25 per cent. of the smears were positive. If other features, including plasma cells, macrophages, and blastoid cells were present, the percentage then rose to 70 . This simple method of screening scrapings can thus indicate those specimens that particularly deserve a protracted search for inclusions, or attempts at cultivation of Chlamydia. In the absence of inclusions, however, the cytological features do not establish a diagnosis of chlamydial infection, nor should they have any diagnostic significance ascribed to them in epidemiological studies.

In addition to these diagnostic methods of demonstrating the presence of chlamydial agents, new serological methods have been developed. The microimmunofluorescence test (Wang and Grayston, 1970) for serotyping subgroup A Chlamydia (C. trachomatis including TRIC agents and LGV agents) has provided a specific diagnostic serological test for chlamydial infection. It can distinguish between infection by subgroup A Chlamydia (C. trachomatis) and infection by subgroup B Chlamydia (C. psittaci) (Dwyer and others, 1972 ; Jones and Treharne, 1974). Using either sera or tears it can frequently indicate the serotype of C. trachomatis-responsible for infection (Dwyer and others, 1972; Hanna, Jawetz, Nabli, Hoshiwara, Ostler, and Dawson, I972 ; Hanna, Jawetz, Briones, Ostler, Keshishayan, and Dawson, I973; Jones, I974; Wang and Grayston, 1974).

It is thus of interest that work done towards the prevention of blindness from trachoma in rural populations has provided methods that have greatly elucidated the common infections of the genital tract (Lancet, 1974) and has also provided greatly improved methods of diagnosing external eye disease in more developed urban clinics. It is to be hoped that the application of these methods in suitably directed field projects in areas of hyperendemic trachoma will lead to advances in the prevention of blindness and morbidity from this persisting chlamydial disease.

However, in addition to TRIC agents, the bacterial pathogens causing seasonal epidemics of acute conjunctivitis have long been held to contribute substantially to the total severity of disease and the ensuing prevalence of blindness in hyperendemic trachoma. Last year, in the October issue, Vastine, Dawson, Daghfous, Messadi, Hoshiwara, Yoneda, and Nataf (1974) reported a study of the late summer epidemic of acute conjunctivitis in children with trachoma in southern Tunisia. Haemophilus sp. was the commonest pathogen found in acute conjunctivitis and there was a high carrier rate for this organism in unaffected eyes. Streptococcus viridans was commonly found in eye cultures from this population but its presence did not correlate with acute conjunctivitis. It is therefore probably not pathogenic. In a controlled trial of Io days of twice-daily topical chemotherapy of trachoma, chlortetracycline and erythromycin eye ointments were found to be equally effective in markedly reducing the prevalence of both purulent conjunctivitis and the prevailing bacterial pathogens in the eye.

In planning public health measures for the control of trachoma, it is clearly of importance adequately to consider the role of both Chlamydia and bacteria, irrespective of whether topical chemotherapy or oral administration of doxycycline is to be used (Hoshiwara, Ostler, Hanna, Gignetti, Coleman, and Jawetz, I973; Jones, 1974). 


\section{References}

Darougar, s., kinnison, J. R., and Jones, B. R. (197I) In "Trachoma and Related Disorders", ed. R. L.

Nichols, p. 50I. Int. Conf. Ser. No. 223. Excerpta Medica, Amsterdam

, KUNDU, D., and JONES, B. R. (1974) Brit. F. Ophthal., 58, 843

DUNLOP, E. M. C., AL-HUSSAINI, M. K., GARLAND, J. A., TREHARNe, J. D., HARPER, I. A., AND JONES, B.R. (I965)

Lancet, I, I I 25 , HARE, M. J., DAROUgar, S., and JONES, B. R. (I97I) In 'Trachoma and Related Disorders', ed.

R. L. Nichols, p. 507. Int. Conf. Ser. No. 223. Excerpta Medica, Amsterdam and Rice, N. s. C. (1969) F. Infect. Dis., 120, 463

DWYER, R. ST. C., TREHARNE, J. D., JONES, B. R., and HERRING, J. (I972) Brit. F. vener. Dis., 48, 452

GEAR, J. H. S., GORDON, F. B., JONES, B. R., and BELl, S. D., JR. (1963) Nature (Lond.) 197, 26

GORDON, F. B. DRESSLER, H. R., and QUAN, A. L. (1967) Amer. F. Ophthal., 63, 1044

and QUAN, A. L. (1965) J. infect. Dis., II5, 186

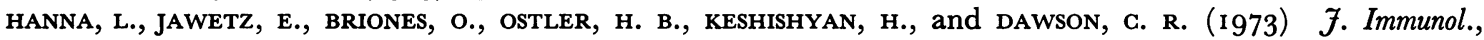
I 10, 1464

, NABLI, B., HOShiWARA, I. OSTlER, B., and DAWSON, G. (I972) Ibid., 108, 102

hoshiwara, i., ostler, h. B., hanna, l., cignetti, f., coleman, v. R., and JaWetz, e. (ig73) 7 . Amer. med.

Ass., 224, 220

JONES, B. R. (I96I) Trans. ophthal. Soc. U.K., 81 367

(1964) Brit. F. vener. Dis., 40, 3

(1974) Brit. F. Ophthal., 58, $43^{8}$

—, AL-hussaini, M. K., and DUNLOP, Е. м. c. (I964) Brit. F. vener. Dis., 40, I9

- COLLIER, L. H., and SMITH, C. H. (1959) Lancet, I, 902

-, and treharne, J. D. (1974) Proc. roy. Soc. Med., 67, 735

KUO, c. c., WANG, s. P., and Grayston, J. T. (1972) J. infect. Dis., 125, 313

Lancet (1974) I, 264 (Editorial)

OSTlER, H. B., SCHACHTER, J., and DAWson, C. R. (ig69) Arch. Ophthal., 82, 587

PAGE, L. A. (1966) Int. F. Syst. Bacteriol., 16, 223 (1968) Ibid., 18, 5 I

SCHACHTER, J., and MEYER, K. F. (I969) J. Bact., 99, 636

-, OSTLER, H. B., and MEYER, K. F. (1969) Lancet, I, I063

TANG, F.-F., GHANG, H-L., hUANG, y-T., and WANG, F. c. (1957) Chin. med. J., 75, 429

TREHARNE, J. D., DAROUgaR, s., and JONES, B. R. (1973) Brit. J. vener. Dis., 49, 295

VASTine, D. W., DAWSON, C. R., DAGHFous, T., MESSADI, M., HOShIWARA, I., YONEDA, C., and NATAF, R. (I974)

Brit. 7. Ophthal., 58, 833

WANG, s-P., and GRAYSTON, J. T. (I970) Amer. 7. Ophthal., 70, 367

- (1974) 7. infect. Dis., $130,3^{88}$

WENTWORTH, B. B., and Alexander, E. R. (1974) Appl. Microbiol. (in press)

WORLD HEALTH ORganization (1973) Wld Hlth Org. Chron., 27, 2 I

YONEDA, C., DAWSON, C. R., DAGHFOUS, T., HOSHIWARA, I., JONES, P., MESSADI, M., and SCHACHTER, J. (I975)

Brit. 7. Ophthal., 59, I 6 